\title{
Control Strategy for Three-Phase Grid-Connected Converters under Unbalanced and Distorted Grid Voltages Using Composite Observers
}

\author{
Thanh Hai Nguyen ${ }^{*}$ and Dong-Choon Lee ${ }^{\dagger}$ \\ ${ }^{\dagger *}$ Dept. of Electrical Engineering, Yeungnam University, Gyeongsan, Korea
}

\begin{abstract}
This paper proposes a novel scheme for the current controller for the grid-side converter (GSC) of permanent-magnet synchronous generator (PMSG) wind turbines to eliminate the high-order harmonics in the grid currents under grid voltage disturbances. The voltage unbalance and harmonics in three-phase systems cause grid current distortions. In order to mitigate the input current distortions, multi-loop current controllers are applied, where the positive-sequence component is regulated by proportional-integral (PI) controllers, and the negative-sequence and high-order harmonic components are regulated by proportional-resonance (PR) controllers. For extracting the positive/negative-sequence and harmonic components of the grid voltages and currents without a phase delay or magnitude reduction, composite observers are applied, which give faster and more precise estimation results. In addition, an active damping method using PR controllers to damp the grid current component of the resonant frequency is employed to improve the operating stability of VSCs with inductor-capacitor-inductor $(L C L)$ filters. The validity of the proposed method is verified by simulation and experimental results.
\end{abstract}

Key Words: Active damping, Composite observer, Grid converter, PMSG, PR controller, Voltage disturbances

\section{INTRODUCTION}

Recently, three-phase AC/DC pulse-width modulation (PWM) converters have become popular in industrial applications such as AC-machine drives, uninterruptible power supplies (UPS), and the integration of renewable energy sources to electric grids [1]-[4]. In particular, the function of the PWM converter is important for grid connection since the grid-connected converter are required to satisfy grid codes and to avoid islanding operation.

To reduce the switching frequency-related harmonics, a single inductor filter has been adopted. These days, $L C L$ filters are being used instead of the $L$ filters to reduce the inductor size while maintaining the same harmonic filtering performance [5]-[7]. $L C L$ filters offer the advantages of low costs and better dynamic performance since the size of the inductors can be reduced when compared with $L$ filters from the view point of the same harmonics. However, $L C L$ filters experience difficulty in the control of the voltage source converter (VSC) since resonance may occur between the grid

Manuscript received Nov. 27, 2012; revised Feb. 5, 2013

Recommended for publication Associate Editor Kyo-Beum Lee.

${ }^{\dagger}$ Corresponding Author: dclee@yu.ac.kr

Tel: +82-53-810-2582, Fax: +82-53-810-4767, Yeungnam University

*Dept. of Electrical Eng., Yeungnam University, Korea

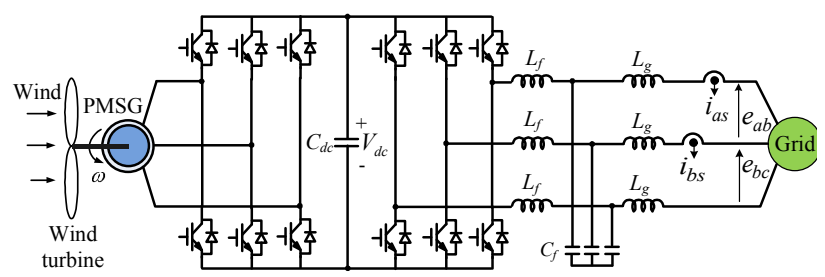

Fig. 1. Full-scale back-to-back converter for wind power system.

and converter sides [7].

There are two types of solutions to damp the resonance. The two methods are passive and active damping. The former method uses an additional resistor connected in series with the filter capacitor [8], [9]. This solution is simple and reliable. However, it lowers the system efficiency due to losses in the resistor. In the latter method, the parameters or structure of the controller are varied [7]. In this method, the resonant component in the grid current is damped by controlling the capacitor voltages or currents [10], [11]. The disadvantages of this method are that additional sensors are required for measuring the voltages or currents and the control ability is highly dependent on the parameters of the LCL filter. 
Another issue in the controller design of grid converters is mitigation of the current distortions due to unbalances and harmonics in the grid voltage. With a single current control loop, the performance of the GSC is deteriorated under grid voltage disturbances since a second-order harmonic voltage component appears at the DC-link [5]. In addition, a large amount of harmonic currents such as the $5^{\text {th }}-, 7^{\text {th }}$ - and higherorder harmonics are produced due to nonlinear loads, which distorts the grid voltages [12]. Harmonic distortions result in power fluctuation in the grid and the possibility of a malfunction of the converter [5], [12]. To overcome these problems, a double-frame current control scheme to eliminate the second-order harmonic voltage component in the DC-link voltage has been proposed, which controls the positive- and negative sequence current components separately [5]. However, the $5^{\text {th }}$ - and $7^{\text {th }}$-order harmonics still influence the current control performance due to the high bandwidth of the current control loop. On the other hand, there exists a method which applies a state observer to compensate for the effects of harmonics and unbalances in the grid voltage [12], where the current harmonics have been eliminated, but the unbalance of the three-phase current still exists. In addition, the application of a composite observer for extracting the harmonic components of the grid voltages and currents to control the grid current has been presented [13].

The contents of the manuscripts have been modified from [13] by adding the composite observer theory, the procedure for selecting the observer gains, and the PLL (phase-locked loop) algorithm, where a novel control scheme based on a composite observer is proposed to mitigate the grid current distortions due to unbalanced and distorted grid voltage conditions for the grid-connected PWM converter (called the grid converter hereafter) of a PMSG wind turbine system, as shown in Fig. 1. The composite observers can extract the fundamental and high-order harmonic components of the grid voltages and currents precisely without any magnitude reduction or phase delay. Then, the positive- and negativesequence components are separated from the fundamental components by all-pass filters. The grid current components are regulated by a multi-loop harmonic current controller, in which the positive-sequence component is regulated by PI controllers and the negative-sequence and harmonic components are regulated by PR controllers. This approach allows the unbalanced and distorted components in the grid current to be eliminated from the system. The PR controllers are also used to damp the resonant grid current components at the resonant frequency, in which the resonant grid currents are extracted by band-pass filters (BPF). An advantage of this active damping method is that no additional hardware is required. The effectiveness of the proposed scheme is verified by simulation and experimental results.

\section{DESCRIPTION OF GRID CONVERTERS}

\section{A. Converter Modeling}

The system considered in this work is shown in Fig. 1. The PMSG wind turbine system is controlled using a fullscale back-to-back converter, in which the PWM converter is connected to the grid through $L C L$ filters. Here, the $L C L$ filters consist of grid- and converter-side filter inductors, $L_{g}$ and $L_{f}$, respectively, and a filter capacitor, $C_{f}$. The grid voltages and currents are measured for the purpose of the converter control. The grid converter can be represented in the $d q$-synchronous reference frame (SRF) with the filter capacitor neglected, as follows [5]:

$$
\begin{aligned}
& e_{d}=R_{t} i_{d}+L_{t} \frac{d i_{d}}{d t}+v_{d}-\omega_{e} L_{t} i_{q} \\
& e_{q}=R_{t} i_{q}+L_{t} \frac{d i_{q}}{d t}+v_{q}-\omega_{e} L_{t} i_{d}
\end{aligned}
$$

where $L_{t}=L_{f}+L_{g}$ and $R_{t}=R_{f}+R_{g}$ are the total inductance and resistance, respectively, from the GSC interfacing to the grid, $\omega_{e}$ is the grid angular velocity, and $e_{d q}$ and $v_{d q}$ are the $d q$-axis grid and converter voltages, respectively. The resonant frequency, $f_{\text {res }}$, of the $L C L$ filters is given by [5]:

$$
f_{\text {res }}=\frac{1}{2 \pi} \sqrt{\frac{L_{f}+L_{g}}{C_{f} L_{f} L_{g}}} .
$$

The filter parameters are determined by the requirements of the current ripples on the grid and converter sides. In addition, the resonant frequency ranges between ten times the grid frequency and half of the switching frequency [7].

\section{B. Effects of Grid Voltage Disturbances}

Three-phase grid voltages often contain unbalanced and distorted components due to the single-phase load and nonlinear loads, in which the $5^{\text {th }}$ - and $7^{\text {th }}$-order harmonic components are significant. Therefore, in this study, the unbalanced components and the $5^{\text {th }}$ - and $7^{\text {th }}$-order harmonics in the grid voltage are taken into account. The grid voltage vector, $e^{s}(t)$, in the stationary reference frame can be expressed as:

$$
e^{s}(t)=\left(E^{p} e^{j \omega_{e} t}+E^{n} e^{-j \omega_{e} t}+E^{5 t h} e^{-j 5 \omega_{e} t}+E^{7 t h} e^{j 7 \omega_{e} t}\right)
$$

where $E^{p}, E^{n}, E^{5 t h}$, and $E^{7 t h}$ are the magnitude of the positive-, negative-, $5^{\text {th }}$ - and $7^{\text {th }}$-order components, respectively.

Then, the grid voltage vector in the synchronous reference frame rotating in the direction of the positive sequence is expressed as:

$$
\begin{aligned}
e^{e}(t) & =e^{s}(t) \cdot e^{-j \omega_{e} t} \\
& =\left(E^{p}+E^{n} e^{-j 2 \omega_{e} t}+E^{5 t h} e^{-j 6 \omega_{e} t}+E^{7 t h} e^{j 6 \omega_{e} t}\right) .
\end{aligned}
$$




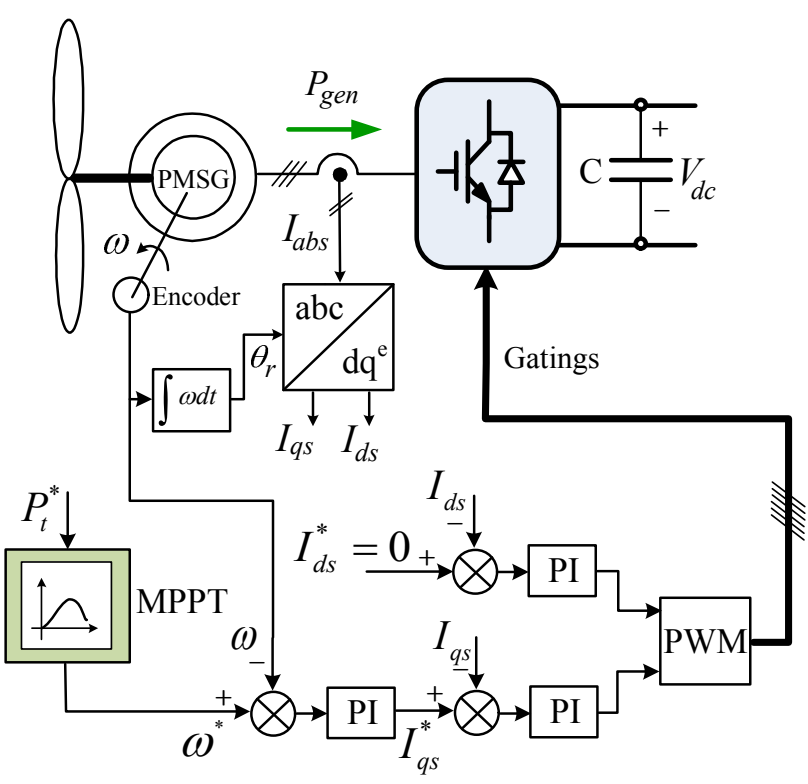

Fig. 2. Control block diagram of the PMSG.

It can be seen from (4) that the grid voltage in the synchronous reference frame appears as DC-quantities for the positive-sequence component and as the second-order harmonics for the negative-sequence component, whereas the $5^{\text {th }}$ - and $7^{\text {th }}$-order harmonics appear as the $6^{\text {th }}$-order harmonic component.

The unbalanced and distorted components of the grid voltage cause distortions of the grid current, which also contains unbalanced and high-order harmonic components [14]. Therefore, it is desirable to mitigate the distortions and unbalances in the grid currents for power quality issues and safe operation of the grid converter.

\section{PMSG WIND TURBINE SYSTEMS}

The main elements of a PMSG wind turbine system are the turbine blades, drive train, PMSG, and back-to-back converters. The turbine power extracted from the wind depends on the turbine blade characteristics, and is expressed by the power coefficient and the tip-speed ratio. The optimal output power of the turbine is captured at the optimal tipspeed ratio. Obviously, the turbine speed varies according to the wind speed so that the optimal tip-speed ratio is maintained.

A control block diagram of a PMSG wind turbine system is shown in Fig. 2. In order to capture the optimal power from the turbine, the MPPT (maximum power point tracking) method is applied [15], which provides the speed reference for the outer speed control loop of the PMSG control. For the PMSG control, the field-oriented control is applied, where the $d$-axis stator current is controlled to zero, and then the $q$-axis stator current is proportional to the active power, which is determined by the speed controller.

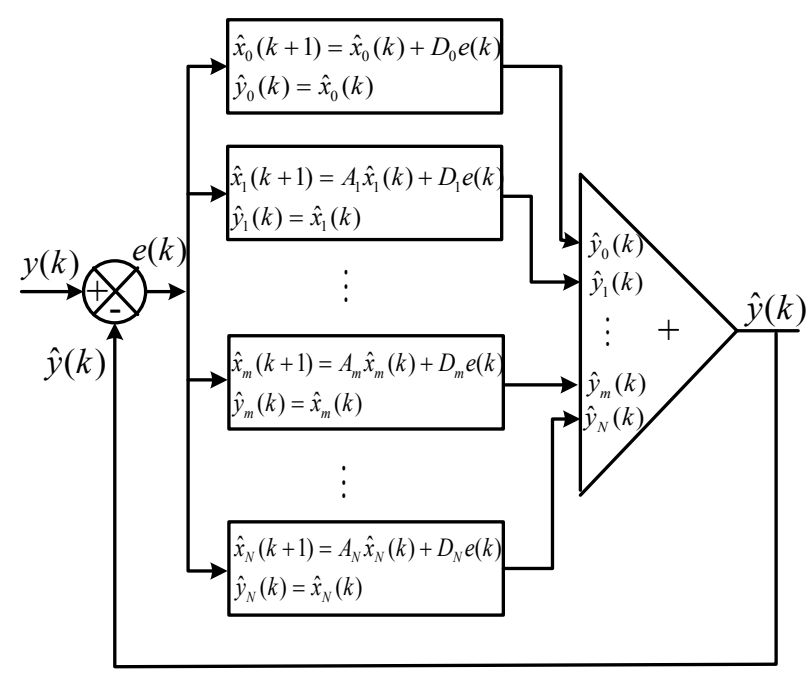

Fig. 3. Structure of the composite observer.

\section{COMPOSITE OBSERVERS}

\section{A. Discrete Composite Observer}

A composite observer is used to extract the individual harmonic components from a periodic signal which is composed of the DC component, $\mathrm{y}_{0}(\mathrm{t})$, and the fundamental and high-order harmonic components, $\mathrm{y}_{1}(\mathrm{t}), \ldots, \mathrm{y}_{\mathrm{N}}(\mathrm{t})$, respectively, where $N$ is the maximum number of harmonic components [16], [17]. For practical applications, the composite observer is usually designed in the discrete time domain, which can be easily implemented by a digital signal processor (DSP). The periodic signal, $y(t)$, of the angular frequency, $\omega_{1}$, is expressed in the discrete time domain as:

$$
y(t) \leftrightarrow y(k T)
$$

where $t=k T$ for $\mathrm{k}=0,1,2, \ldots, \infty$, and $T$ is the sampling time.

The state equation for the discrete observer is expressed as:

$$
\left\{\begin{array}{l}
x(k+1)=A x(k) \\
y(k)=B^{t} x(k)
\end{array}\right.
$$

where $\mathrm{x}(\mathrm{k})$ is a state vector, $\mathrm{y}(\mathrm{k})$ is an output vector, and

$$
A=\left[\begin{array}{ccccccc}
A_{0} & 0 & 0 & \cdots & 0 & \cdots & 0 \\
0 & A_{1} & 0 & \cdots & 0 & \cdots & 0 \\
0 & 0 & A_{2} & \cdots & 0 & \cdots & 0 \\
& & \vdots & & & & \\
0 & 0 & 0 & \cdots & A_{m} & \cdots & 0 \\
& & \vdots & & & & \\
0 & 0 & 0 & \cdots & 0 & \cdots & A_{N}
\end{array}\right]
$$

with $\mathrm{A}_{0}=0$ and 


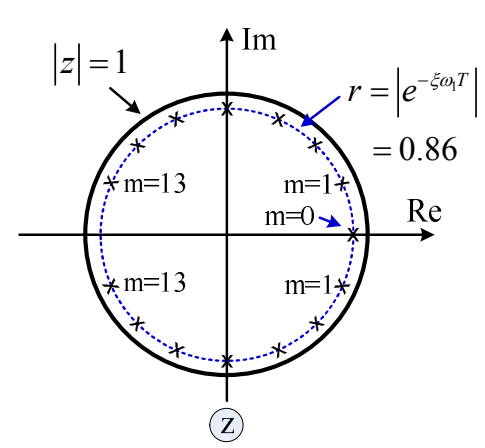

Fig. 4. Pole locations in z-plane for voltage and current observers.

$$
A_{m}=\left[\begin{array}{cc}
\cos \left(m \cdot \omega_{1} T\right) & \cos \left(m \cdot \omega_{1} T\right)-1 \\
\cos \left(m \cdot \omega_{1} T\right)+1 & \cos \left(m \cdot \omega_{1} T\right)
\end{array}\right]
$$

and $B^{t}=\left[\begin{array}{llllllll}1 & 1 & 0 & 1 & 0 & \cdots & 1 & 0\end{array}\right]$.

Fig. 3 shows a block diagram of a discrete composite observer, in which the composite observer is modeled in a closed-loop linear system as [16]-[18]:

$$
\left\{\begin{array}{l}
\hat{x}(k+1)=A \hat{x}(k)+D e(k) \\
\hat{y}(k)=B^{t} \hat{x}(k)
\end{array}\right.
$$

where the subscript "^" indicates the estimated value and $D$ is a gain vector as:

$$
\begin{aligned}
D & =\left[D_{0}, D_{1}, \cdots, D_{m}, \cdots, D_{N}\right]^{t} \\
& =\left[d_{0},\left(d_{11}, d_{12}\right), \cdots,\left(d_{m 1}, d_{m 2}\right), \cdots,\left(d_{N 1}, d_{N 2}\right)\right]^{t}
\end{aligned}
$$

The $m^{\text {th }}$ sub-block, shown in Fig. 3, is expressed by the state vector $\hat{x}_{m}(k)$ and the output variable $\hat{y}_{m}(k)$ as:

$$
\left\{\begin{array}{l}
\hat{x}_{m}(k+1)=A_{m} \hat{x}_{m}(k)+D_{m} e(k) \\
\hat{y}_{m}(k)=B_{m}^{t} \hat{x}_{m}(k) ; \quad m=0,1,2, \cdots, N
\end{array}\right.
$$

where $B_{m}^{t}=\left[\begin{array}{ll}1 & 0\end{array}\right]$ and the state vector $x_{m}(k)=\left[x_{m 1}(k), x_{m 2}(k)\right]^{t}$. Then the output variable $y_{m}(k)=x_{m 1}(k)$, and the observer error is defined as:

$$
e(k)=y(k)-\not y(k)=B^{t}[x(k)-x(k)]=B^{t} E(k) .
$$

From (5), (6), and (8), the difference equation for the error term is obtained as:

$$
E(k+1)=\left(A-D B^{t}\right) E(k) .
$$

Then, the characteristic equation can be written in the $z$ domain as:

$$
\operatorname{det}\left[z I-A+D B^{t}\right]=0
$$

where $\mathrm{I}$ is a $(2 \mathrm{~N}+1) \mathrm{x}(2 \mathrm{~N}+1)$-dimensional identity matrix.

By the pole placement technique, the observer poles, which are the $(2 \mathrm{~N}+1)$ roots of the characteristic equation, are located within the unit circle in the z-plane to stabilize the closed-loop observer. Then, the observer poles are chosen as

$$
z=e^{-\xi \omega_{1} T}\left[\cos \left(m \omega_{1} T\right) \pm j \sin \left(m \omega_{1} T\right)\right]
$$

where $\xi$ is a tunable parameter, which locates the observer poles within the unit circle in the z-plane. Then, from (10) and (11), the gain vector $\mathrm{D}$ is determined.

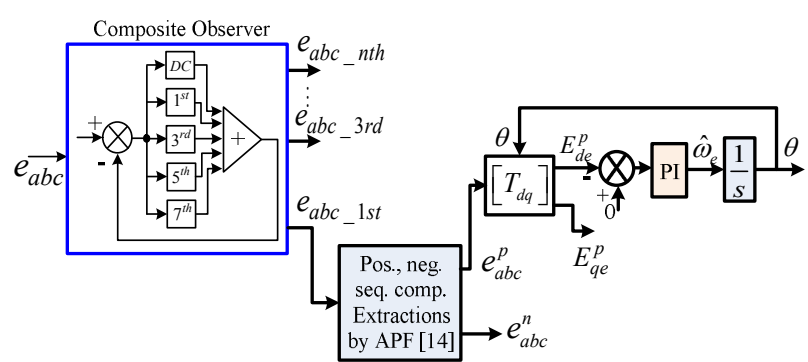

Fig. 5. Block diagram of PLL.

\section{B. Extraction of the Harmonic Components of the Grid Voltage and Current}

Under grid voltage distortions, the grid-phase voltages and currents contain a lot of harmonics. Thus separate composite observers are applied to extract these components. In this study, for the three-phase system, the distorted gridphase voltage, $e_{s x}(x=a, b, c)$, can be modeled in the discrete time domain as:

$$
e_{s x}(k)=\sum_{m=1}^{N} e_{s x, m}(k), m=0,1,3,5, \cdots, 13
$$

where $m$ is the $m^{\text {th }}$-harmonic order.

In the observer design, the nominal frequency of the grid is $60 \mathrm{~Hz}$, the sampling time is $200 \mu \mathrm{s}$, and $\xi=2$ is selected. Then, the fifteen pole locations of the discrete observer are shown in Fig. 4.

Similarly, the harmonic components of the grid-phase currents are extracted with the aforementioned procedure.

\section{CONTROL OF GRID-SIDE CONVERTERS}

The function of the grid converters for wind power applications is to deliver the power generated from the wind generator to the grid by keeping the DC-link voltage constant. The cascaded control structure is employed with the outer control loop of the DC-link voltage. The inner control loop regulates the grid currents to be sinusoidal and balanced even under unbalanced and distorted grid voltages. Thus the unbalanced and distorted grid current components are controlled to zero. By designing the resonant frequency of the $L C L$ filter to be lower than half of the switching frequency, the resonant component of the grid currents can be damped by PR controllers.

\section{A. Phase-Locked Loop under Unbalanced and Distorted Grid Voltages}

Under the conditions of unbalanced and distorted grid voltages, the fundamental and high-order harmonic components of the grid voltage, $e_{a b c_{-} 3 r d}, \ldots, e_{a b c_{-} n t h}$ and $e_{a b c_{-} 1 s t}$, are extracted by the composite observer. From the fundamental component, the positive- and negative-sequence components are separated by all-pass filters (APF) [19], [20].

Then, the positive-sequence components in the $a b c$-frame are transformed into the $d q$ rotating-reference frame. A three- 
phase phase-locked loop (PLL) based on the synchronous reference frame is used for the positive-sequence voltage components, in which the $d$-axis voltage component is regulated to zero by a feedback loop [21]. The phase angle is determined by the output of the feedback loop. Fig. 5 shows a block diagram to estimate the phase angle of the grid voltage.

\section{B. Proposed Control Scheme for Grid-Side Converter}

Fig. 6 shows a block diagram of the proposed current control based on the composite observer of a GSC, which consists of an outer DC-link voltage control loop and inner current control loops.

First, the fundamental and harmonic components of the grid voltages and currents, $e_{a b c_{-} 1 s t}, e_{a b c_{-} 3 t h}, \ldots, e_{a b c_{-} n t h}$ and $i_{a b c_{-} 1 s t}, i_{a b c_{-} 3 t h}, \ldots, i_{a b c_{-} n t h}$, respectively, are extracted by the composite observers. Then, the positive- and negative-sequence $d q$-components with high-order harmonics are obtained, as shown in Fig. 5. It can be seen that by Park's transformation with $\theta$, the positive-sequence $d q$-axis components are transformed as DC-quantities, whereas those of the negative sequence become second-order components. In addition, the $d q$-axis components of the $5^{\text {th }}$ - and $7^{\text {th }}$ - order harmonics contain $6^{\text {th }}$-order components.

In order to control the aforementioned current components, a multi-loop current control structure is applied, in which the positive-sequence component is regulated by PI controllers. The $q$-axis current command is generated from the DC-link voltage controller to regulate the active power flow to the grid. The $d$-axis current is controlled to zero to obtain a unity power factor. Meanwhile, PR regulators tuned at $120 \mathrm{~Hz}$ and $360 \mathrm{~Hz}$ are employed to control the negativesequence and harmonic components $\left(5^{\text {th }}\right.$ and $7^{\text {th }}$-order $)$, respectively, to be zero to deliver sinusoidal and balanced currents to the grid.

In addition, a PR controller at the resonant frequency is used to damp the resonant component in the grid currents. In this study, the resonant frequency of the LCL filters is designed as $830 \mathrm{~Hz}$ which is about one-third of the switching frequency $(2.5 \mathrm{kHz})$. BPFs with a cut-off frequency of 830 $\mathrm{Hz}$ and a quality factor of 4.15 are applied to extract the resonant component of the grid currents.

\section{Simulation Results}

PSIM simulation results have been shown to verify the validity of the proposed control strategy for the three-phase GSC used for a 2-MW PMSG wind turbine application. The specifications of the GSC and the PMSG are listed in Table I and Table II, respectively. The grid voltage and frequency are $0.69 \mathrm{kV}$ and $60 \mathrm{~Hz}$, respectively. The DC-link capacitance is $24 \mathrm{mF}$, and the DC-link voltage is controlled at $1.2 \mathrm{kV}$.

The switching frequency of the back-to-back converter is $2.5 \mathrm{kHz}$. For the discrete composite observer design, the fundamental frequency is chosen as $60 \mathrm{~Hz}$, and the sampling period is $200 \mu \mathrm{s}$. Fig. 7 shows the estimation performance of the composite observers, in which the grid phase voltages and currents are estimated well, as shown in Fig. 7(a) and (b), respectively.

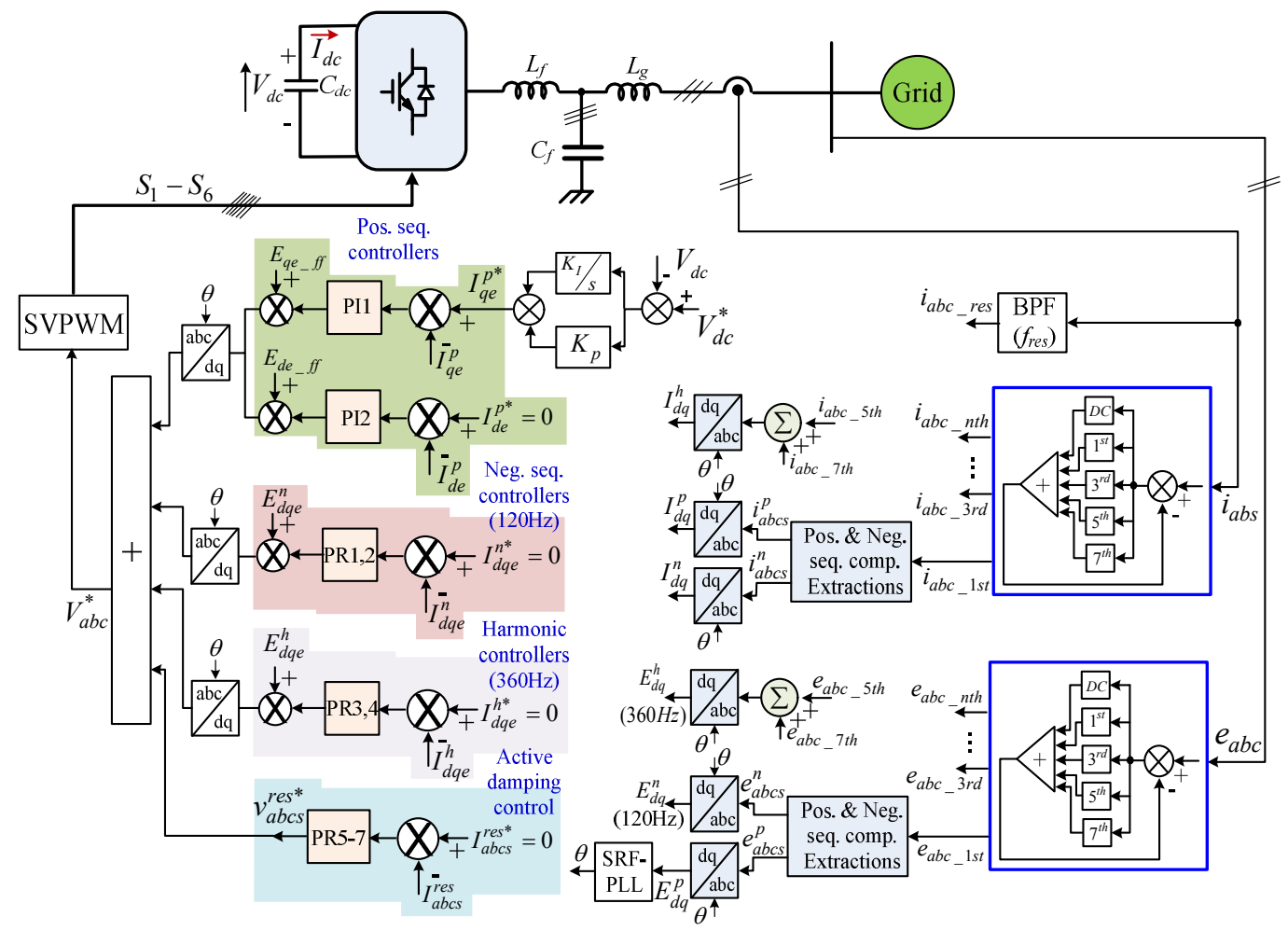

Fig. 6. Control block diagram of the current control based on composite observer for the GSC. 


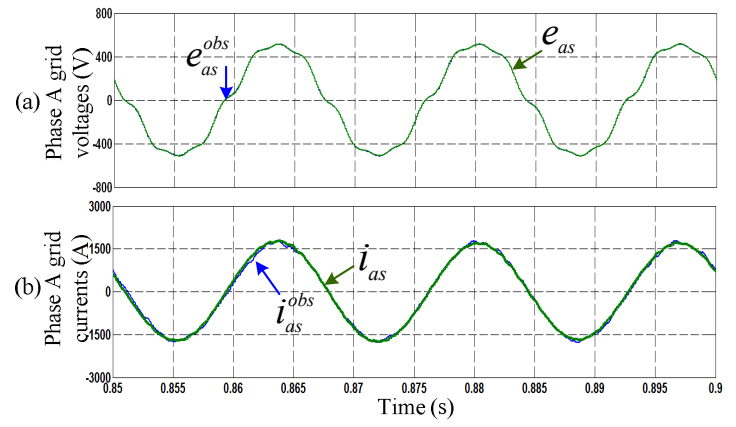

Fig. 7. Estimation performance of composite observer. (a) Grid voltages. (b) Grid currents.

TABLE I

SPECIFICATIONS OF GRID PWM CONVERTER

\begin{tabular}{|c|c|}
\hline Parameters & Values \\
\hline Rated power & $2 \mathrm{MW}$ \\
\hline Grid voltage & $690 \mathrm{~V} / 60 \mathrm{~Hz}$ \\
\hline Grid/converter filter inductances & $0.1 / 0.126 \mathrm{mH}$ \\
\hline Shunt filter capacitance & $656 \mathrm{uF}$ \\
\hline
\end{tabular}

TABLE II

SPECIFICATIONS OF PMSG

\begin{tabular}{|c|c|}
\hline Parameters & Values \\
\hline Rated power & $2 \mathrm{MW}$ \\
\hline Stator voltage/frequency & $690 \mathrm{~V} / 16.6 \mathrm{~Hz}$ \\
\hline Stator resistance/inductance & $8.556 \mathrm{~m} \Omega / 3.59 \mathrm{mH}$ \\
\hline Number of poles & 120 \\
\hline
\end{tabular}

Fig. 8 shows the performance of the PLL under unbalanced and distorted grid voltages. Fig. 8(a) shows the grid voltages, which contain 5\% fifth- and seventh-order harmonics each and a $20 \%$ drop in the two phase voltages at $0.8 \mathrm{~s}$. It can be seen in Fig. 8(b) that the positive-sequence components of the grid voltages are sinusoidal and balanced. Fig. 8(c) shows the phase angle of the positive-sequence voltage component, which is estimated well under unbalanced and distorted grid voltages. The $d q$-axis grid voltage components are shown in Fig. 8(d), in which the $d$ axis component is set at zero for the grid voltage orientation. The $q$-axis component is the magnitude of the positivesequence voltage component.

In the grid voltage disturbances, it is assumed that the PMSG wind turbine is operated under the constant wind speed condition, and that the grid converter is connected to distorted grid voltages containing 5\% fifth- and seventh-order harmonics, as shown in Fig. 9(a).

Fig. 9 shows the response of the GSC, in which the grid currents are almost sinusoidal, as shown in Fig. 9(b). The fundamental components of the grid currents are controlled well, as shown in Fig. 9(c), in terms of the $d-q$ components. The DC-link voltage is controlled well at its reference of $1,200 \mathrm{~V}$, which is shown in Fig. 9(d).

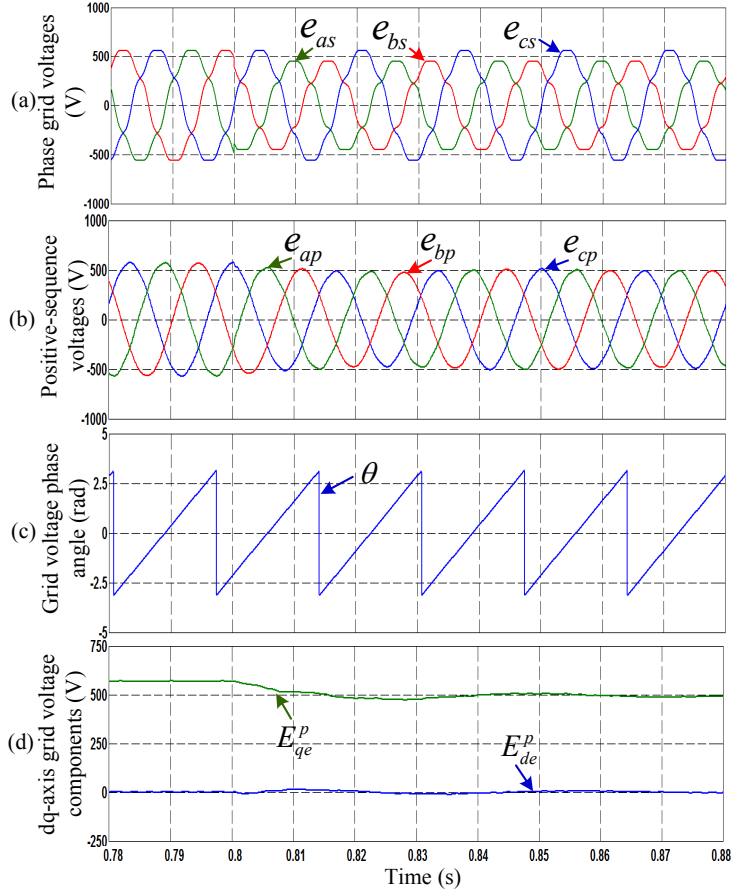

Fig. 8. PLL performance in unbalanced and distorted grid voltages. (a) Grid voltages. (b) Positive-sequence components. (c) Phase angle. (d) $d q$-axis grid voltage components.

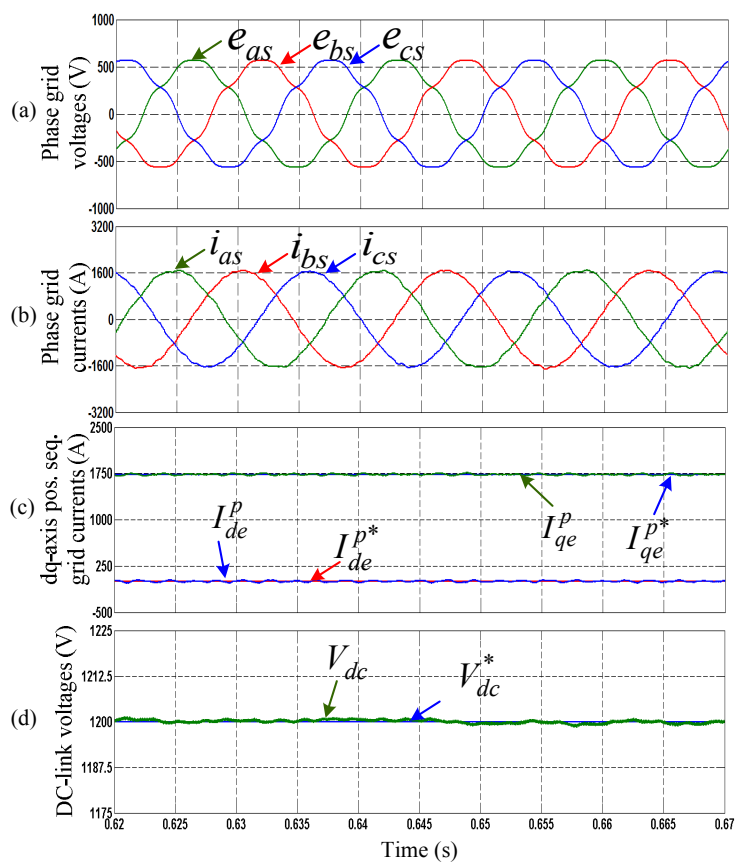

Fig. 9. Control performance of GSC under distorted grid voltages. (a) Phase grid voltages. (b) Phase grid currents. (c) $d q$-axis grid currents. (d) DC-link voltage.

Fig. 10 shows the response of the GSC under the condition of distorted and unbalanced grid voltages, where $5 \%$ fifth and seventh-order harmonics are included and a 20\% drop in two phase voltages occurs at $0.8 \mathrm{~s}$, as shown in Fig. $10(\mathrm{a})$. 

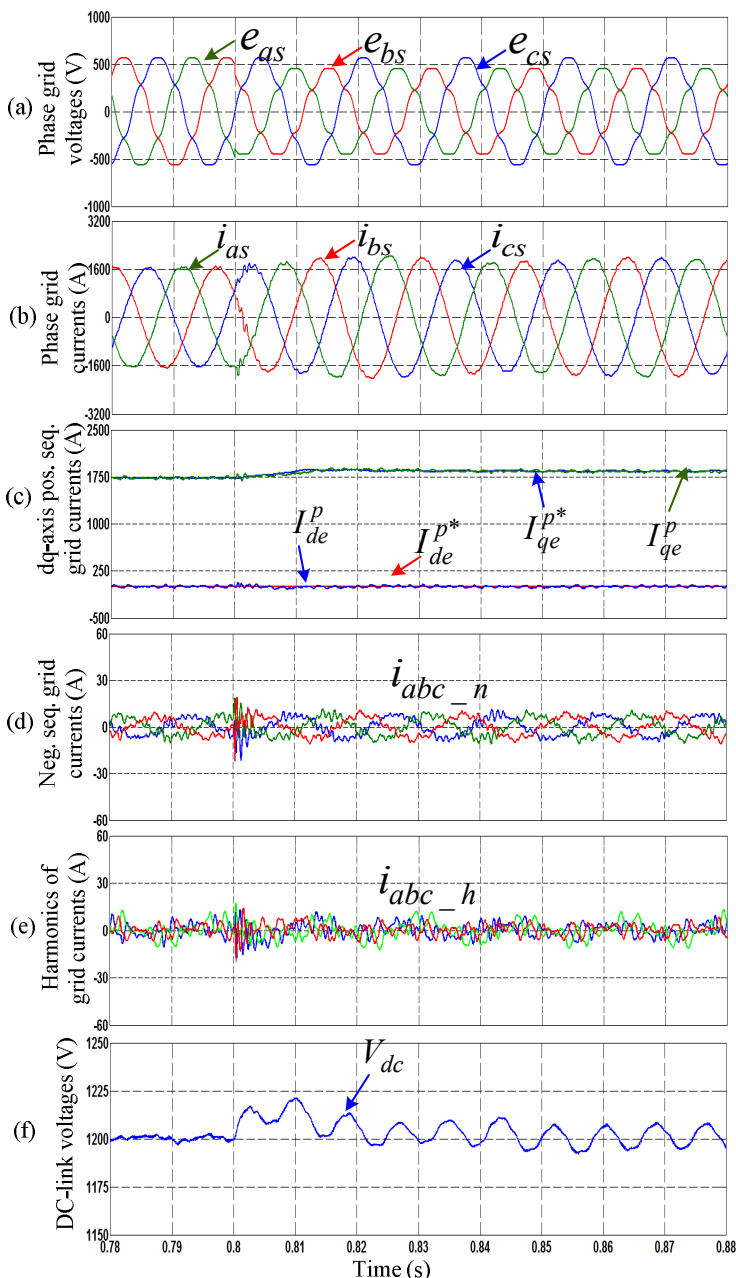

Fig. 10. Response of GSC in the case of distortion and unbalance of grid voltage. (a) Grid voltages. (b) Grid currents. (c) $d q$-axis pos. seq. grid currents. (d) Neg. seq. grid currents. (e) Gird current harmonics. (f) DC-link voltage.

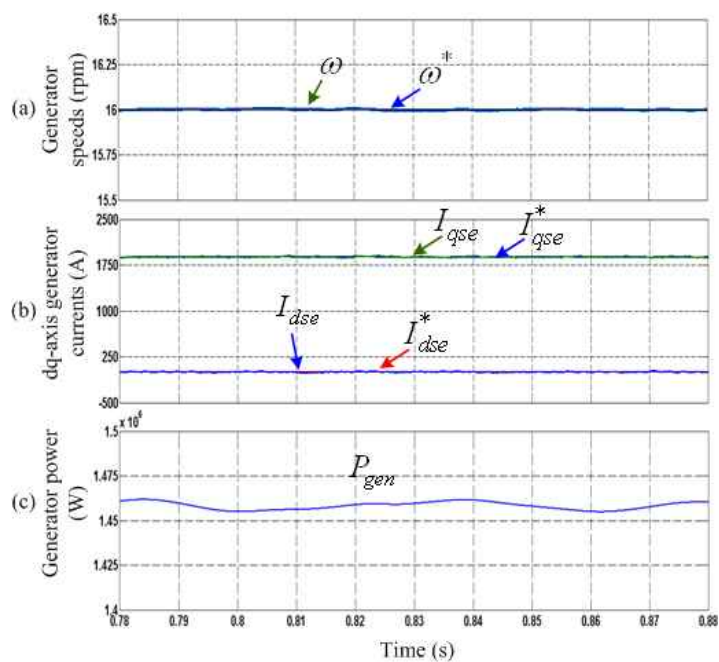

Fig. 11. Control performance of PMSG. (a) Generator speeds. (b) $d q$-axis generator currents. (c) Generator power.

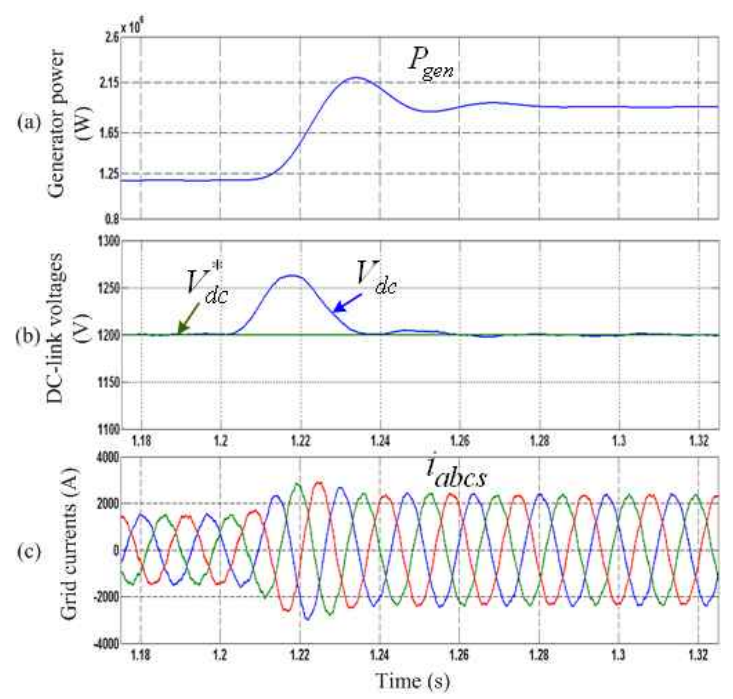

Fig. 12. Response of GSC in transient state. (a) Generator power. (b) DC-link voltages. (c) Grid currents.

It can be seen in Fig. 10(b) that the grid currents are almost sinusoidal and balanced even for distorted and unbalanced grid voltages. The $d q$-axis positive-sequence grid current components are controlled well, as shown in Fig. 10(c). Here, the $q$-axis component, regulating the active power, is increased when the grid voltage is reduced, whereas the $d$ axis component, controlling the reactive power, is controlled to zero to obtain a unity power factor. The negative-sequence and high-order harmonic components of the grid currents are also controlled to zero, as shown in Fig. 10(d) and (e), respectively. Fig. 10(f) shows the DC-link voltage, which is kept close to its nominal value of $1,200 \mathrm{~V}$ in the steady state. In addition, the voltage overshoot in the transient states is about $20 \mathrm{~V}$ (about $1.67 \%$ when compared to its average). It can also be seen in Fig. 10(f) that the voltage ripples appear in the DC-link due to unbalanced grid voltages.

The generator control performance is shown in Fig. 11. Fig. 11(a) shows the generator speed, which follows its reference well. The $d q$-axis generator currents are shown in Fig. 11(b), in which the $d$-axis current is controlled to zero. Fig. 11(c) shows the generator power.

An investigation in the case of wind speed varying from $8.5 \mathrm{~m} / \mathrm{s}$ to $10 \mathrm{~m} / \mathrm{s}$ is performed to illustrate the validity of the proposed control strategy for the GSC. The generator power is increased from 1.15 MW to 1.9 MW, as shown in Fig. 12(a). In this case, the DC-link voltage is still kept close to its reference of 1,200 V, as shown in Fig. 12(b), in which the voltage overshoot is about $5 \%$. In addition, the grid currents are still controlled well, and are sinusoidal and balanced, as shown in Fig. 12(c).

\section{EXPERIMENTAL RESULTS}

To verify the feasibility of the proposed control scheme for grid converters, experimental tests on a $3 \mathrm{~kW}$ laboratory 


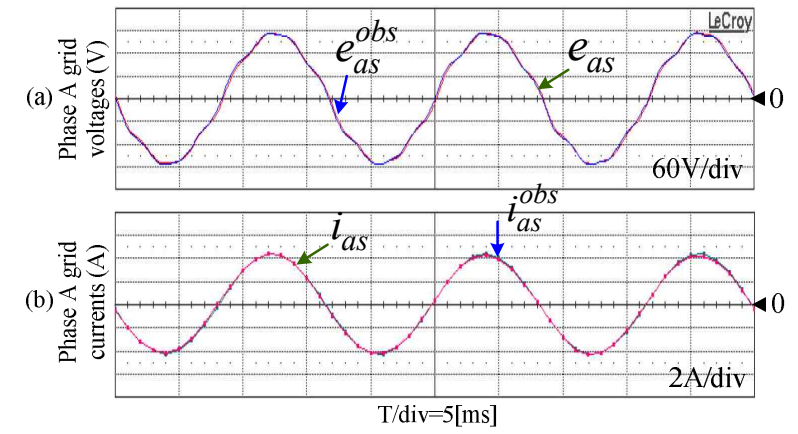

Fig. 13. Estimation performance of composite observer. (a) Grid voltages. (b) Grid currents.

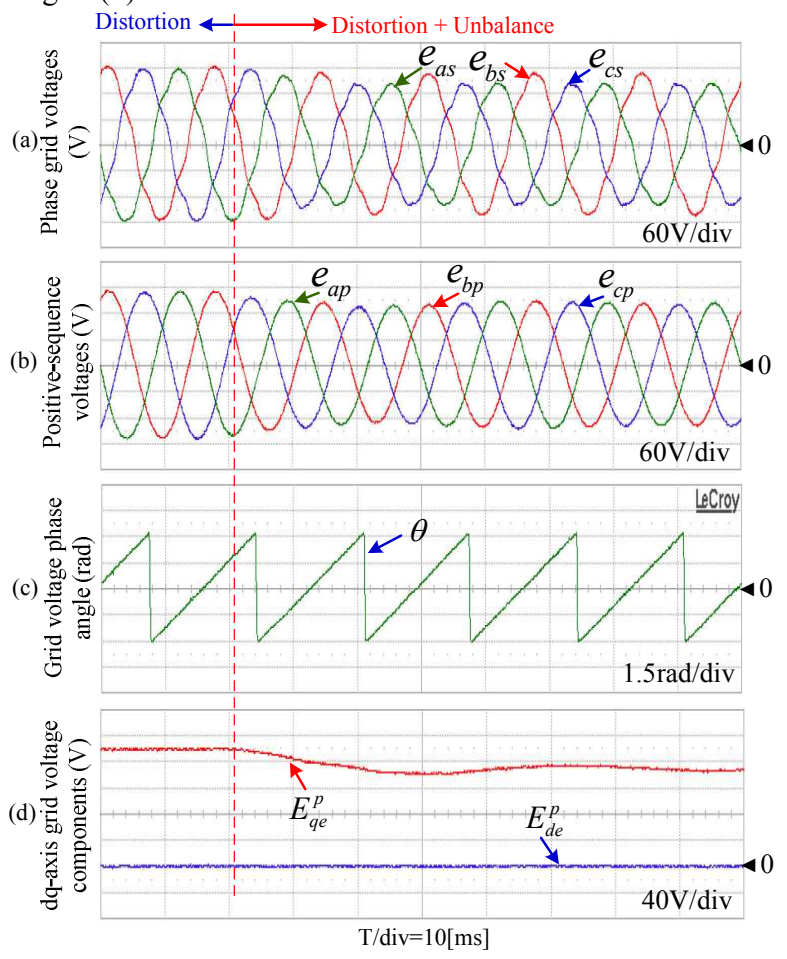

Fig. 14. PLL performance in unbalanced and distorted grid voltages. (a) Grid voltages. (b) Positive-sequence components. (c) Phase angle. (d) $d q$-axis grid voltage components.

TABLE III

SPECIFICATIONS OF GSC (EXPERIMENT)

\begin{tabular}{|c|c|}
\hline Parameters & Values \\
\hline Rated power & $3 \mathrm{~kW}$ \\
\hline Grid voltage & $220 \mathrm{~V} / 60 \mathrm{~Hz}$ \\
\hline Grid/converter filter inductances & $0.7 / 1.1 \mathrm{mH}$ \\
\hline Shunt filter capacitance & $10 \mu \mathrm{F}$ \\
\hline DC-link capacitance & $1,650 \mu \mathrm{F}$ \\
\hline
\end{tabular}

prototype were carried out. The parameters of the converter are listed in Table III. The grid voltage is $220 \mathrm{~V} / 60 \mathrm{~Hz}$ and a $10 \mathrm{kVA}$ grid simulator is used for generating the voltage unbalance and distortion. The DC-link voltage is controlled at $340 \mathrm{~V}$. The switching frequency of the converter is $5 \mathrm{kHz}$. The digital controllers are based on a TMS320VC33 DSP chip. For the discrete composite observer design, the nominal frequency of the grid is $60 \mathrm{~Hz}$.

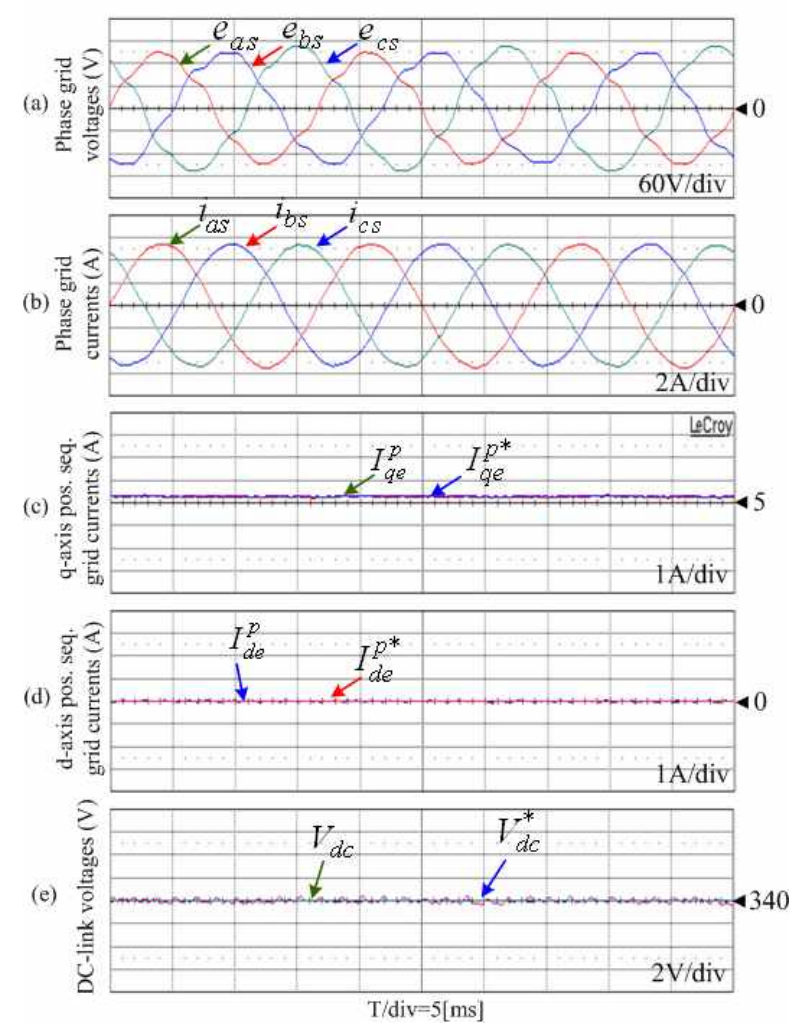

Fig. 15. Response of GSC under distorted and unbalanced voltage conditions. (a) Grid voltages. (b) Grid currents. (c) $q$-axis grid currents. (d) $d$-axis grid currents. (e) DC-link voltages.

The sampling period is $100 \mu \mathrm{s}$. The resistors are connected at the DC-link for the load tests.

Fig. 13 shows the online extraction performance using the composite observer. The grid phase voltages are shown in Fig. 13(a), in which the estimated voltage tracks the measured voltage well. In addition, it can be seen from Fig. 13(b) that the extracted grid current and the measured one are the same.

The performance of the PLL under unbalanced and distorted grid voltages is shown in Fig. 14. Fig. 14(a) shows the grid voltages, where $5 \%$ fifth- and seventh-order harmonics are included, and a $23 \%$ voltage drop in phases $\mathrm{A}$ and $\mathrm{C}$ and a $5 \%$ voltage drop in phase $\mathrm{B}$ occur at $22 \mathrm{~ms}$. The positive-sequence components of the grid voltages are sinusoidal and balanced, as shown in Fig. 14(b). Fig. 14(c) shows the phase angle of the positive-sequence voltage component, which is estimated well under unbalanced and distorted grid voltages. Fig. 14(d) shows the $d q$-axis grid voltage components.

Fig. 15 shows the performance of the grid converter under the aforementioned grid voltage distortion and unbalance condition, as shown in Fig. 15(a). The grid currents are controlled to be sinusoidal and balanced, as shown in Fig. 15(b), even under distorted and unbalanced grid voltages. The fundamental grid current components, which appear as a DC quantity, are controlled well, as shown in Fig. 15(c) and (d) 


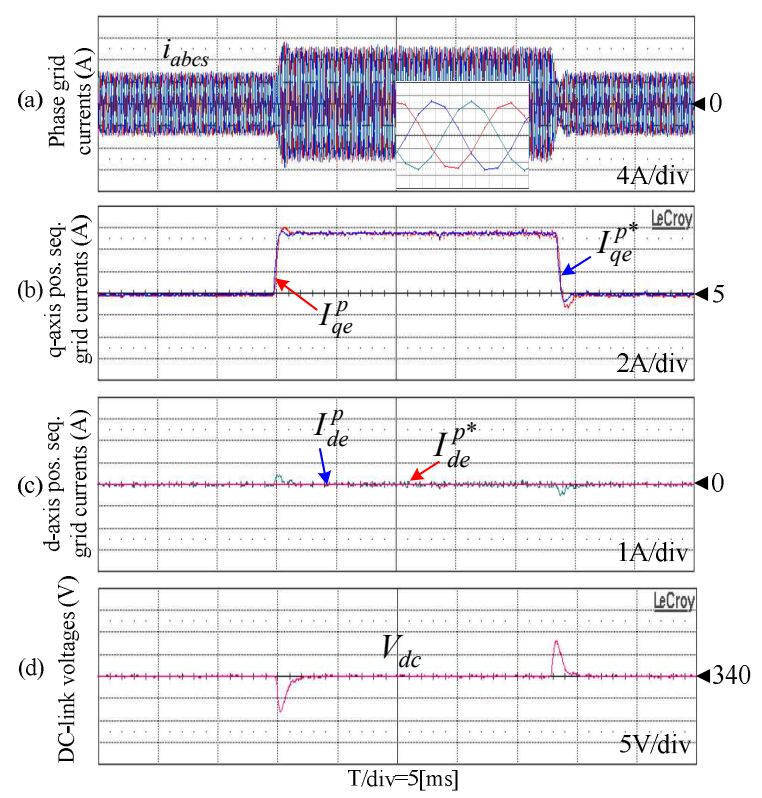

Fig. 16. Performance of GSC in transient states. (a) Phase grid currents. (b) $q$-axis phase grid currents. (c). $d$-axis phase grid currents. (d) DC-link voltage.

for the $q$ - and $d$-axis currents, respectively, in which the $d$ axis current is controlled to zero. Fig. 15(e) shows the DClink voltage, which follows its reference well at $340 \mathrm{~V}$.

Fig. 16 shows the control performance of the grid converter in the transient state by varying the load from 1.3 $\mathrm{kW}$ to $2.6 \mathrm{~kW}$ and then back to $1.3 \mathrm{~kW}$. Fig. 16(a) shows the balanced and non-distorted grid current waveforms, where the magnified ones are also shown in the same grid. In the transient states, the fundamental grid current components are still controlled well. Fig. 16(b) shows the $q$-axis grid currents, where the actual current follows its reference well and has a low overshoot in transient states. It can be seen in Fig. 16(c) that the $d$-axis current is still controlled well to zero for the unity power factor operation. Fig. 16(d) shows the DC-link voltage, which is still kept close to its reference of $340 \mathrm{~V}$. The overshoot value in transient states is about $8 \mathrm{~V}$, which is less than $2.5 \%$ when compared with its average.

\section{CONCLUSIONS}

A novel control scheme for the grid converter of PMSG wind turbine systems has been proposed to mitigate the grid current distortion due to grid voltage disturbances. A composite observer has been employed to extract the positive-sequence, negative-sequence and harmonic components of the grid voltages and the currents are extracted precisely. With this control scheme, the current control performance of the grid converter has been improved significantly, and the unbalanced and high-order harmonic components of the grid current are controlled to zero by PR regulators. Thus the currents flowing into the grid are almost sinusoidal and balanced even under grid voltage distortions and unbalance. The validity of the proposed algorithm has been verified by simulation and experimental results.

\section{ACKNOWLEDGEMENT}

This research was supported by the Yeungnam University research grant in 2010.

\section{REFERENCES}

[1] K. Hatua, A. K. Jain, D. Banerjee, and V. T. Ranganathan, "Active damping of output LC filter resonance for vectorcontrolled VSI-fed AC motor drives," IEEE Trans. Ind. Electron., Vol. 59, No. 1, pp. 334-342, Jan. 2012.

[2] D.-E. Kim and D.-C. Lee, "Feedback linearization control of three-phase UPS inverter systems," IEEE Trans. Ind. Electron., Vol. 57, No. 3, pp. 963-968, Mar. 2010.

[3] M. Liserre, R. Teodorescu, and F. Blaabjerg, "Stability of photovoltaic and wind turbine grid-connected inverters for a large set of grid impedance values," IEEE Trans. Power. Electron., Vol. 21, No. 1, pp. 263-272, Jan. 2006.

[4] X. Zhang, W. Pan, Y. Liu, and D. Xu, "Improved grid voltage control strategy for wind farm with DFIG connected to distribution networks," Journal of Power Electronics, Vol. 12, No. 3, pp. 495-502, May 2012.

[5] H.-S. Song and K. Nam, "Dual current control scheme for PWM converter under unbalanced input voltage conditions," IEEE Trans. Ind. Electron., Vol. 46, No. 5, pp. 953-959, Oct. 1999.

[6] J. Dannehl, C. Wessels, and F. Wilhelm, "Limitations of voltage-oriented PI current control of grid-connected PWM rectifiers with LCL filters," IEEE Trans. Ind. Electron., Vol. 56, No. 2, pp. 380-388, Feb. 2009.

[7] J. Dannehl, M. Liserre, and F. Wilhelm, "Filter-based active damping of voltage source converters with LCL filters," IEEE Trans. Ind. Electron., Vol. 58, No. 8, pp. 3623-3632, Aug. 2011.

[8] X. Wang, X. Ruan, S. Liu, and C. K. Tse, "Full feedforward of grid voltage for grid-connected inverter with LCL filter to suppress current distortion due to grid voltage harmonics," IEEE Trans. Power. Electron., Vol. 25, No. 12, pp. 3119-3127, Dec. 2010.

[9] Y. A. R. I. Mohamed, "Mitigation of dynamic, unbalanced, and harmonic voltage disturbances using grid-connected inverters with LCL filter," IEEE Trans. Ind. Electron., Vol. 58, No. 9, pp. 3914-3924, Sep. 2011.

[10] E. Twining and D. G. Homles, "Grid current regulation of a three-phase voltage source inverter with an LCL input filter," IEEE Trans. Power. Electron., Vol. 18, No. 3, pp. 888-895, May. 2003.

[11] F. Liu, Y. Zhou, S. Duan, J. Yin, and F. Liu, "Parameter design of a two-current-loop controller used in a gridconnected inverter system with LCL filter," IEEE Trans. Ind. Electron., Vol. 56, No. 11, pp. 4483-4491, Nov. 2009.

[12] K. Lee, T. M. Jahns, T. A. Lipo, V. Blasko, and R. D. Lorenz, "Observer-based control methods for combined source-voltage harmonics and unbalance disturbances in PWM voltage-source converters," IEEE Trans. Ind. Appl., Vol. 45, No. 6, pp. 2010-2021, Nov./Dec. 2009.

[13] T. H. Nguyen and D.-C. Lee, "Control of three-phase grid converters based on composite observer for unbalanced and distorted grid voltage," in Proc. IEEE ISIE, May. 2012, pp. 1874-1879. 
[14] S. Alepuz, S. B. Monge, J. Bordonau, J. A. M. Velasco, C. A. Silva, J. Pontt, and J. Rodriquez, "Control strategies based on symmetrical components for grid-connected converters under voltage dips," IEEE Trans. Ind. Electron., Vol. 56, No. 6, pp. 2162-2173, Jun. 2009.

[15] R. Data and V. T. Ranganathan, "A method of tracking the peak power points for a variable speed wind energy conversion system," IEEE Trans. Energy Convers., Vol. 18, No. 1, pp. 163-168, Mar. 2003.

[16] K. Selvajyothi and P. A. Janakiraman, "Reduction of voltage harmonics in single phase inverters using composite observers," IEEE Trans. Power Del., Vol. 25, No. 2, pp. 1045-1057, Apr. 2010.

[17] K. Selvajyothi and P. A. Janakiraman, "Extraction of harmonics using composite observers," IEEE Trans. Power Del., Vol. 23, No. 1, pp. 31-40, Jan. 2008.

[18] T. H. Nguyen, D.-C. Lee, and S.-G. Lee, "Sinusoidal current control of single-phase PWM converters under voltage source distortion using composite observer," Trans. of KIPE, Vol. 16, No. 5, pp. 466-476, Oct. 2011.

[19] S.-K. Sul, Control of electric machine drive systems, Wiley, 2011.

[20] A. O. Ibrahim, T. H. Nguyen, D.-C. Lee, and S.-C. Kim, “A fault ride-through technique of DFIG wind turbine systems using dynamic voltage restorers," IEEE Trans. Energy Convers., Vol. 26, No. 3, pp. 871-882, Sep. 2011.

[21] P. Rodriguez, J. Pou, J. Bergas, J. I. Candela, R. P. Burgos, and D. Boroyevich, "Decoupled double synchronous reference frame PLL for power converters control," IEEE Trans. Power Electron., Vol. 22, No. 2, pp. 584-592, Mar. 2007

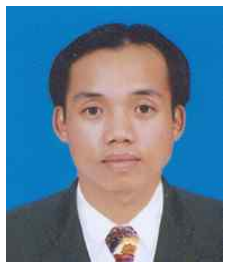

Thanh Hai Nguyen was born in Dong Thap, Vietnam. He received his B.S. in Engineering from the Ho Chi Minh City University of Technology, Ho Chi Minh City, Vietnam, in 2003, and his M.S. from the Department of Electrical Engineering, Yeungnam University, Gyeongbuk, Korea, in 2010, where he is currently working toward his Ph.D. degree. He was an Assistant Lecturer in the College of Technology, Can Tho University, Can Tho, Vietnam, in 2003. His current research interests include power converters, machine drives, and wind power generation.

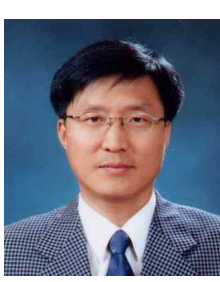

Dong-Choon Lee received his B.S., M.S., and $\mathrm{Ph} . \mathrm{D}$. in Electrical Engineering from Seoul National University, Seoul, Korea, in 1985, 1987, and 1993, respectively. He was a Research Engineer with Daewoo Heavy Industry, Korea, from 1987 to 1988. Since 1994, he has been a faculty member in the Department of Electrical Engineering, Yeungnam University, Gyeongbuk, Korea. As a Visiting Scholar, he joined the Power Quality Laboratory, Texas A\&M University, College Station, TX, USA, in 1998, the Electrical Drive Center, University of Nottingham, Nottingham, U.K., in 2001, the Wisconsin Electric Machines \& Power Electronic Consortium, University of Wisconsin, Madison, Wisconsin, USA, in 2004, and the FREEDM Systems Center, North Carolina State University, Raleigh, North Carolina, USA, from September 2011 to August 2012. His current research interests include ac machine drives, control of power converters, wind power generation, and power quality. Prof. Lee is currently a Publication Editor of the Journal of Power Electronics of the Korean Institute of Power Electronics. 